\title{
Application of distributed temperature sensors in piping-prone dikes
}

\author{
S Bersan University of Padova, Italy \\ AR Koelewijn Deltares, Netherlands \\ P Simonini University of Padova, Italy
}

\begin{abstract}
In the past two decades, Distributed Temperature Sensing (DTS) systems have been installed in a number of dams with the aim of detecting internal erosion. The functioning principle is based on the fact that the temperature distribution inside an embankment dam changes when a leakage occurs. In addition to the benefits given by the use of optical fibres in lieu of electrical sensors, a major advantage of this technique lies in its high spatial resolution (up to two measurements per metre) achievable over long distances with a single sensor. DTS looks also promising for the monitoring of dikes prone to piping. With this term, we address the mechanism that occurs under hydraulic structures lying on a permeable and erodible foundation soil. The temperature variations measured so far by DTSs at the initial stage of piping are of little extent, thus the detection of piping when there is still time for intervention before the dike collapses is not straightforward. The effectiveness of a fibre-optic DTS system to detect piping has been tested in a large-scale failure test run in the Netherlands in 2012 on a dike built on purpose for the experiment. This paper describes the set-up of the experiment and presents the temperature data obtained. A thorough analysis of the data gives insights on the process of heat transfer under a dike as well as on the development and evolution of thermal anomalies around leakages. It emerged that the onset of thermal anomalies around piping channels, and so their magnitude, depends on a number of site specific factors, among which the duration of the flood event. The minimum acceptable specifications of a DTS system for real-time piping detection are also discussed.
\end{abstract}

\section{Introduction}

Internal erosion occurring in (or underneath) water retaining structures is a phenomenon hard to identify with traditional geotechnical instrumentation, because it does not generate substantial deformations (before collapse) and its effect on porewater pressures is highly localised. Both theoretical considerations (Ng \& Oswalt 2010) and the field data presented in this paper show that the radius of the depression cone generated by an erosion channel is on the order of few metres. Consequently, a monitoring system relying on porewater pressure measurements would require an uneconomical number of sensors, even for short stretches of embankment to control.

In the last decades, many efforts have been made to identify new parameters linked to seepage and internal erosion, which are measurable by means of extensive technologies. Among these are electrical resistivity, self-potential, emissivity and temperature (Sheffer et al. 2009). Detection of internal erosion via temperature measurements relies on the principle that a localised increase of the seepage flow velocity causes the temperature field to change inside the embankment.

Temperature measurement is gaining increasing acceptance as a method to monitor seepage in embankment dams (Johansson \& Sjödahl 2009). A French electricity company has done a number of installations along its channel dikes and, based on the data collected in such dikes, has developed advanced mathematical and statistical interpretation tools (Beck et al. 2010). Almost no installations so far concern river or sea dikes. 
Backward erosion is a form of internal erosion that may occur in dispersive clays, non-plastic silts or sands of a foundation or core of a dam or dike. A distinction can be made between pipe formation in a near-horizontal direction below a cohesive layer - this is known as backward erosion piping - and global backward erosion, where near-vertical pipes form in non-plastic embankment cores (ICOLD 2015).

Although not many collapses induced by backward erosion piping have been documented, due to the difficulty in recognising clearly the traces of the mechanism before and even after the collapse occurred, piping is among the major causes of dike collapse both in the Netherlands (Vrijling 2010) and in northern Italy (Cirio et al. 2004).

In the following, we present and discuss temperature data collected in a large-scale failure test carried out in the Netherlands on a standard dike built for the experiment.

\subsection{Distributed temperature sensors}

The use of temperature as seepage tracer applies to dams since the 1950s. In the first applications, however, temperature was measured using point sensors deployed in standpipes at different depths. Only after the development of fibre-optic DTS technology, temperature became measurable in an extensive manner, as optical cables can provide a continuous measurement of temperature along their length for more than $1 \mathrm{~km}$. Details on the functioning principles of fibre-optic sensors are given in Henault et al. (2010). Optical cables can be buried directly in the soil and run for some $\mathrm{km}$ along the embankment. In existing embankments, optical cables can be installed in narrow ditches excavated at the toe.

The adoption of optical fibres in dams dates back to the early 1990s (Johansson \& Sjödahl 2004); the first test installation in a dike was made in 1995 by EdF, in France (Fry 1997). Nowadays, after increasing their performances and becoming available on the market at acceptable costs, DTS systems are adopted worldwide for dam monitoring. The costs of the system ranges from EUR 5 to $7 / \mathrm{m}$ for the cable and from EUR 25,000 to 50,000 for the datalogger. The costs of a piezometer pressure sensor, required about every metre, range from EUR 500-700 including installation. A break-even point between both systems is reached for a dike stretch as short as about $50 \mathrm{~m}$.

\subsection{Use of thermometry as a detection tool for internal erosion}

Temperature can be used as an indirect measure of the saturation degree of a soil, exploiting the dependency of the thermal properties of the soil (conductivity and heat capacity) on its water content. Moreover, in saturated conditions, thermography can provide information on seepage velocities. When the porewater is stagnant or moves slowly (Darcy velovity lower than $10^{-6}$ to $10^{-7} \mathrm{~m} / \mathrm{s}$ ) heat transfer occurs merely by conduction, as in solids. Above that threshold, advection, i.e. heat transport operated by the moving fluid, prevails and the temperature field in the soil depends on the extent of the fluid flow.

By exploiting this phenomenon, it is possible to identify erosion channels (pipes) and areas of higher permeability produced by washout of finer particles (suffusion).

There are two approaches to detect seepage. The first approach, named gradient method, is a passive method based on absolute temperature changes caused by seepage water within the dam. This method is limited to cases with a temperature gradient between the seepage water and the dam material. To surpass this limitation an active approach is used, also named heat-pulse method. This method is mostly used in combination with fibre-optic hybrid sensing cables, which couple the optical fibre with electric cables. When heating the cable for a short period, cable sections within zones of higher water saturation, or even flow zones, appear as sections with increased heat transport, i.e. they heat up less (Dornstädter 2013).

\subsection{Piping mechanism}

This article focuses on backward erosion piping occurring in the previous foundations of embankments, where the erosion process is essentially horizontal. 
If the pervious layer is not protected by filters or intact blanket layers, erosion starts at the exit point at the downstream toe when the flow velocity is large enough to transport the grains. Right under the cohesive material, of which the embankment is made, this does not lead to an immediate collapse of the overlying material, thus a pipe forms, usually leading to a sand boil at the exit point. With a further increase of the head, the pipe grows further and, after reaching a certain length, it continues to grow, even if the head does not further increase. The corresponding head is often referred to as the critical head. Once the upstream side has been reached, the pipe starts to enlarge from the upstream side, often leading to an observable increase in discharge and sediment load, finally leading to failure. This may be caused by an excessive flow through the pipe, or by collapse of the roof of the pipe causing settlement of the crest of the dike. Such a collapse may initially lead to a total blocking of the flow, but then the erosion process will start again and, inevitably, failure will occur unless the head is decreased. A more detailed description of the process is given by Van Beek et al. (2013).

\section{$2 \quad$ Methodology}

\subsection{The IJkdijk test program}

The IJkdijk (Dutch for 'calibration dike') is a Dutch research program initiated in 2005 with the double goal of testing new monitoring techniques under field conditions and advancing the knowledge on geotechnical failure mechanisms on a large scale. In the past eight years, various large-scale experiments, mainly on dikes, have been carried out at a special test site at Booneschans, in the Northeast of The Netherlands. The program included an overtopping test on a $4 \mathrm{~m}$ high grass slope (2007), a slope stability test of a $100 \mathrm{~m}$ long, $6 \mathrm{~m}$ high dike resting on soft soil (2008), a series of four tests on piping (2009). A conclusive series of tests, which are described in the following section, was carried out in 2012.

\section{$2.2 \quad$ All-in-one sensor validation test}

In 2012 a series of three large-scale tests was carried out in Booneschans under the name of all-in-one sensor validation test (AIO SVT). The first part of the name refers to the fact that every test included more than one single possible failure mechanism. The second part of the name expresses the main purpose of the experiment, i.e. testing the predictive power of levee sensor systems. In addition, the experiment aimed at investigating the effectiveness of failure prevention measures.

The dikes tested were named after their position in the field. East and west dikes had a sandy foundation soil vulnerable to piping and a sandy core vulnerable to micro-instability. The West dike was equipped with two controllable drainage tubes as prevention measures against piping and micro-instability (depending on the location of the tube); the East dike was equipped with a granular filter against piping. The south dike, built on a very soft soil, was tested against slope instability with a deep sliding plane and local instability of the clay cover. In this paper, the piping test run on the West dike is described in detail.

After the collapsed East dike was removed, a new dike was built at the same location, as part of another project aimed at testing the capability of a geotextile filter to prevent piping. A detailed description of all the failure prevention measures tested at the Booneschans test site can be found in Koelewijn et al. (2014).

All the dikes tested were instrumented with both new sensor technology and proven technology as reference monitoring. New sensor technology included remote sensing (ground-based radar, ground-based LiDAR, infrared thermography) and surface geophysical methods (ground penetrating radar, self-potential, passive seismic, electrical resistivity tomography). Fibre-optic sensors were also tested: the dikes were equipped with fibre bragg grating (FBG) pore pressure sensors, FBG strain and temperature sensors and distributed strain and temperature sensors.

The AIO SVT aimed for more than the mere testing of innovative sensor technologies. It aimed at testing the predictive power of full-service levee sensor systems, i.e. sensors (which can be inside the levee or the subsoil, at the surface or remote) combined with data processing and an information system producing a 
timely, reliable warning in case failure may occur. In this framework, tools for real time data visualisation, dike safety assessment and information sharing between stakeholders were also tested.

Twelve companies participated in the test providing sensors (or services) at their own expenses and submitting daily predictions of the failure mode and conditions at which failure would occur. The companies that provided monitoring systems used their own measurements to make predictions, while the companies providing dike safety information systems had access to the data of most of the monitoring systems installed, being validated and shared through a central data base. Subsequently the performances of the monitoring systems were judged by the test leaders according to the following criteria: robustness of the instrumentation, accuracy, density and frequency of the measurements, time for installation and adjustment, processing time, interpretation and quality of prediction. The information systems were judged by their ability to combine data of different sources, the application of various techniques and methods to arrive at meaningful information, the clarity of statements and of course the quality of the prediction. These evaluations can be found in Koelewijn et al. (2013) or, more extensively, in De Vries et al. (2013).

\subsection{The West dike}

The piping tests were carried out in the two basins visible in Figure 1. The West dike (on the right in the picture) was $3.5 \mathrm{~m}$ high, $19 \mathrm{~m}$ long and $15 \mathrm{~m}$ wide at its base. As depicted in Figure 2, the lower part of the dike was made of a $0.7 \mathrm{~m}$ well-compacted clay layer. Given its low permeability, the clay layer separated the hydraulic fluxes occurring in the foundation from the fluxes affecting the embankment. The dike body was made of a $1.7 \mathrm{~m}$ high, less-compacted, small clay dike at the upstream side, a sand core behind the small clay dike and a cover of organic clay. This composition is found in many small dikes around the Netherlands. The foundation consisted of a uniform sand layer with a thickness of $3 \mathrm{~m}$. An impermeable foil separated this test layer from the subsoil. The sand had a $d_{50}$ of $0.30 \mathrm{~mm}$ and a uniformity coefficient $U=d_{60} / d_{10}$ of 1.69 . As can be seen from Figure 1 , a dike ring surrounded the test dike forming a reservoir. This had a volume of about 2,000 $\mathrm{m}^{3}$. A lower dike ring enclosed a downstream basin, necessary to ensure full saturation of the foundation layer and to control the downstream water level. By design, failure could occur from piping through the base, micro-instability of the sand core and overtopping of the crest with subsequent erosion of the downstream slope.

A reference monitoring system using conventional instrumentation was installed to closely monitor the course of the test. It consisted of two pore pressure transducers to record the water levels in the upstream and downstream reservoirs, a flow metre placed at the discharge point of the downstream basin and 77 pore pressure transducers placed in the dike during construction. Four lines of 17 sensors each were installed in the foundation and three lines of three sensors each in the sand core, right above the clay layer. 


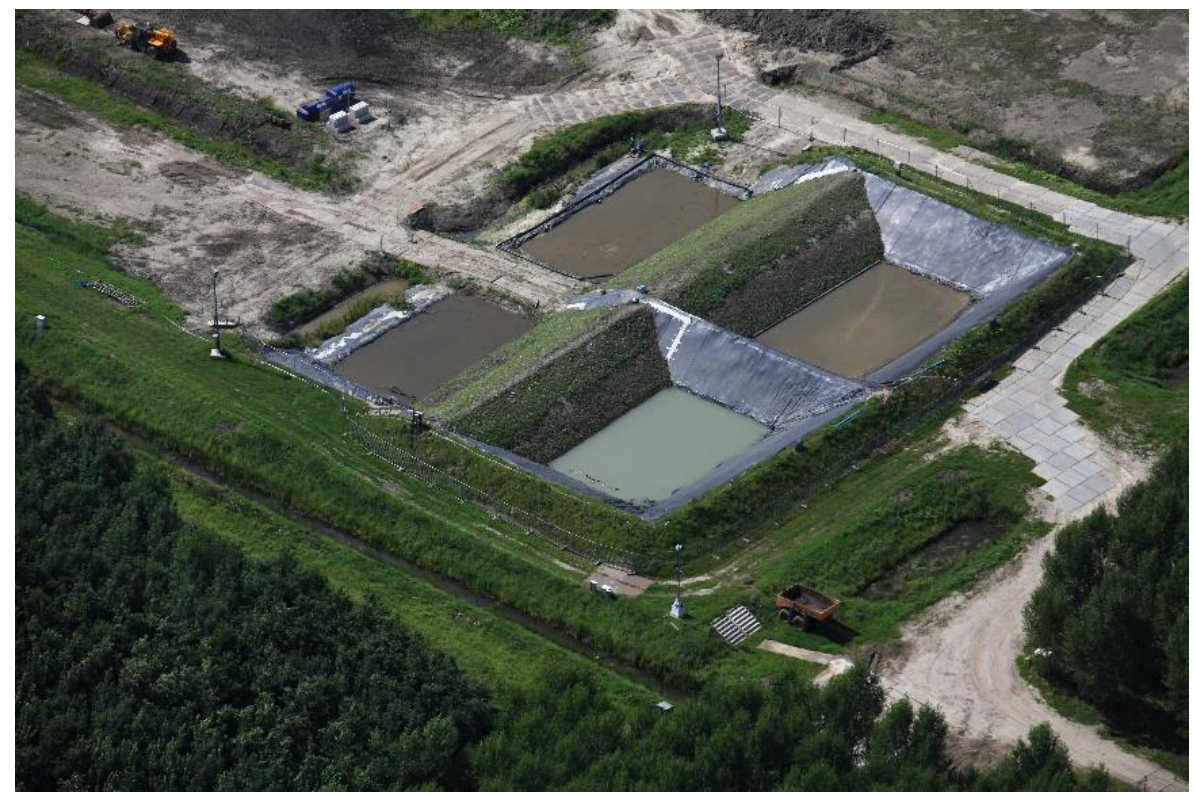

\section{Figure 1 Aerial view of West and East dike (respectively on the right and left of the picture)}

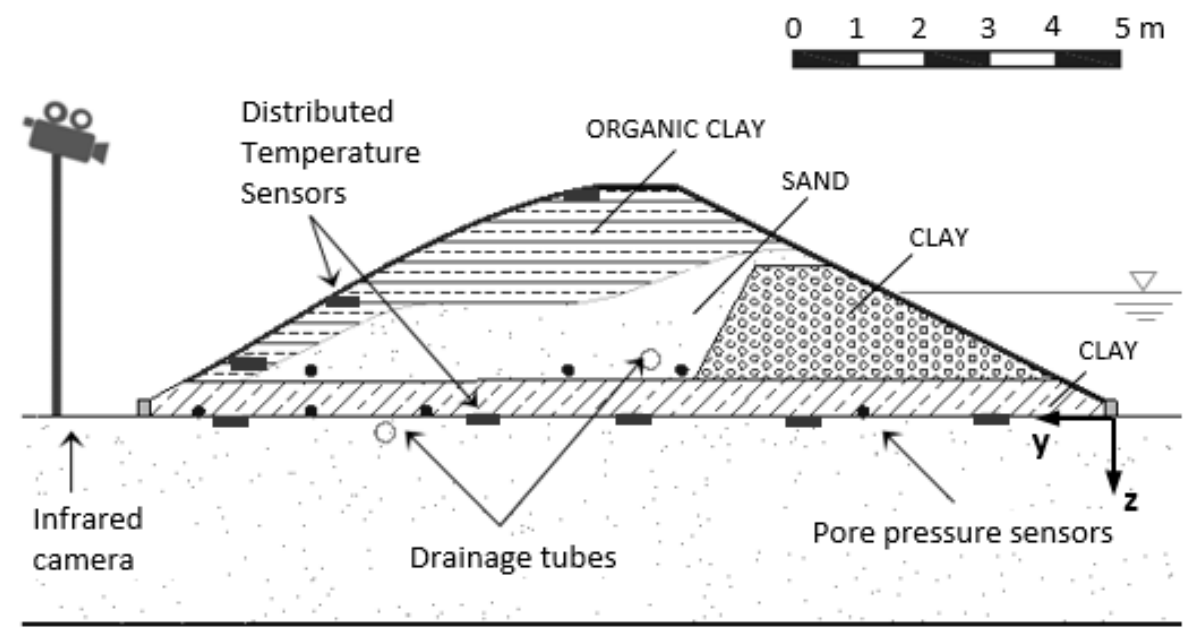

\section{Figure 2 Cross-section of the test dike with positions of pore pressure and temperature sensors}

Visual inspection was performed at regular intervals; position and size of the sand-boils were recorded and documented by pictures. The data of this reference monitoring were not disclosed to the participants during the tests.

Temperature was measured inside the dike by means of distributed sensors, made of optic fibres encased in geotextile strips. Five strips were deployed at the interface between the foundation layer and the clay base at progressive distance from the toe; three strips were deployed on the downstream slope, a few centimetres below the surface. Due to a mistake during installation, temperature was not measured in the upstream basin.

An infrared camera was used to map the surface temperature of the downstream slope as well as part of the upstream and downstream basins.

The test was performed by increasing the water level in the upstream basin in steps, while the downstream basin was maintained at almost constant level. The hydraulic load is reported in Figure 3, right axis. Backward erosion under the dike started after two days of testing, at a creep ratio of $L / H=10(L=$ seepage 
length, $\mathrm{H}=$ hydraulic load). A single sand boil formed right at the toe of the dike, but sand transport stopped soon after, while the load was maintained constant. After a further increase of the hydraulic load, at a creep ratio of $L / H=8.5$, new sand boils developed at the toe and continuous sand transport was observed, as deduced by the size of the sand-boils increasing with time. At this point, partial opening of the lower drainage tube had a clear effect on the sand transport that suddenly stopped. After one day, the tube was closed to bring the dike to collapse and erosion restarted. The dike failed on the fifth day, not because of under-excavation from backward erosion, but because the saturation line in the sand core had touched the toe and caused the body of the dike to liquefy.

\section{$3 \quad$ Data}

\subsection{Reference monitoring data}

The bulk hydraulic conductivity of the sand layer was calculated from the flow measurements performed before piping occurred and after an equilibrium situation was found in the pore pressure readings: an average value of $1.25 \mathrm{E}-4 \mathrm{~m} / \mathrm{s}$ was obtained.

The combination of careful visual inspection and pore pressure measurements allowed for a detailed reconstruction of the development of the pipes during the test.

Traces of sand transport induced by the seepage flow, consisting of grain movements or spots of turbid water, were recorded since 21.5 hours $(\mathrm{h})$, yet the first proper sand boil was only discovered at $45 \mathrm{~h}$, placed at $x=5.2 \mathrm{~m}$ ( $\mathrm{x}$-axis in the longitudinal direction of the dike, starting at the west side). The trace of the first pipe was detected 2 hours earlier in the pore pressure measurements: among the transducers located at about $0.9 \mathrm{~m}$ from the downstream toe $(y=14.1 \mathrm{~m}$; $y$-axis starting at the upstream toe of the dike, see Figure 2). Those placed at $x=4.8 \mathrm{~m}$ and $\mathrm{x}=5.8 \mathrm{~m}$ showed a drop soon after the hydraulic load had been raised to $1.5 \mathrm{~m}$ (Figure 3, lower bundle of curves). The pressure drop measured is of small extent, likely because the sensor was likely not located exactly in the piping channel and the draining effect of the pipe decreases very fast sideways with distance. At $55.5 \mathrm{~h}$, after a further increase of the upstream water level, the first pressure drop occurred in the line of pore pressure transducers placed at $2.5 \mathrm{~m}$ from the downstream toe $(y=12.5 \mathrm{~m}$ ) (Figure 3, upper bundle of curves), indicating that one piping channel had grown that far. From that moment on, sand transport occurred continuously, as revealed by the size of the sand boils increasing with time. 


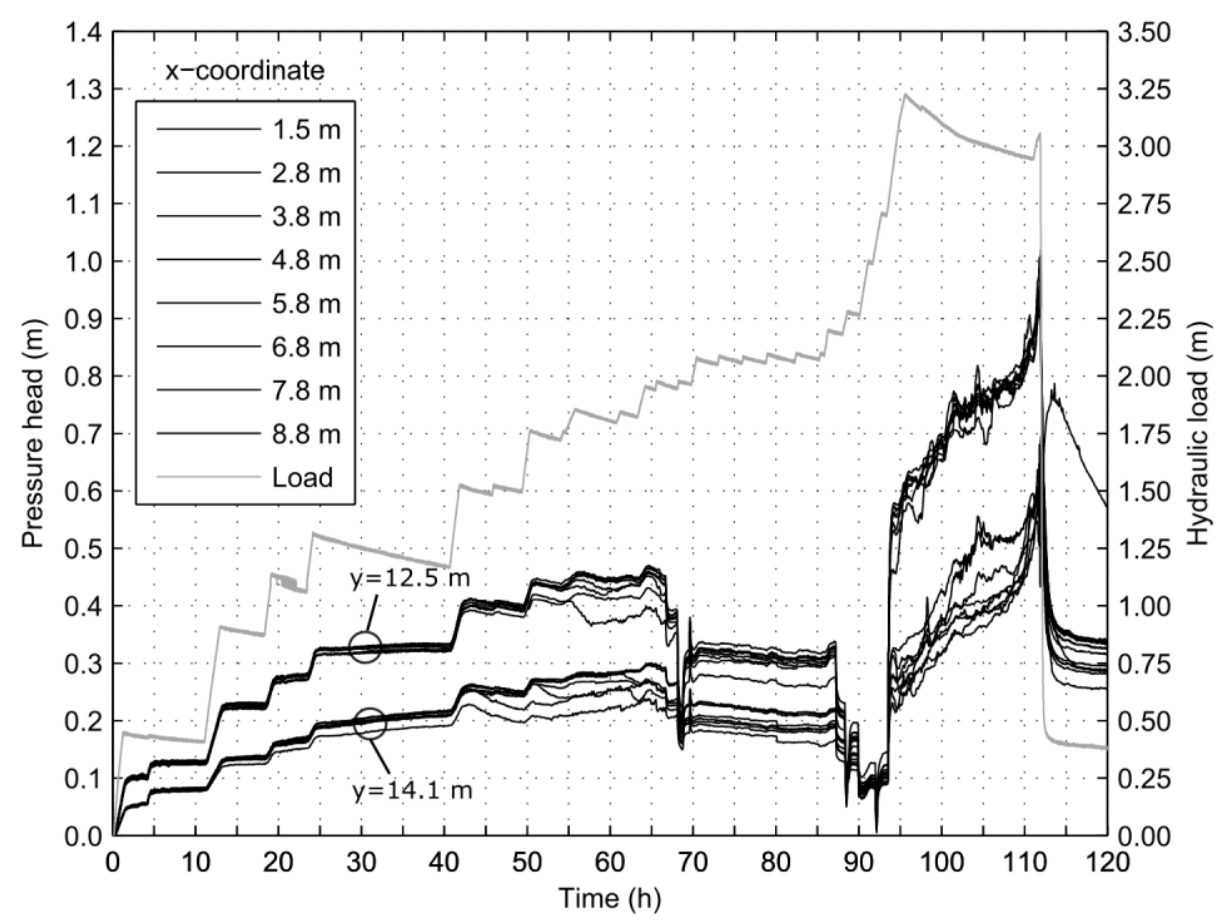

\section{Figure 3 Hydraulic load applied to the dike and pressure head measured under the dike at two distances from upstream}

The opening of the lower drainage tube, starting at $67 \mathrm{~h}$, had a clear effect on the pore pressures under the dike and, in turn, an effect on the sand transport that suddenly stopped. After closing the controllable drainage tube at around $94 \mathrm{~h}$, the pore pressures were restored again and the piping erosion process restarted as before. However, from the pore pressure measurements (not reported here) it is possible to assert that none of the pipes reached the third line of sensors, placed at about a quarter of the seepage length.

\subsection{Temperature data}

The measurements started seven days before the beginning of the test and were interrupted before the end of the test, when the fibres broke due to the sliding of a large portion of the downstream slope. Thanks to the distribute nature of the sensor, temperature was measured along the entire cable and an average value was provided each metre with a frequency of 30 minutes and a resolution of $0.1^{\circ} \mathrm{C}$.

We present in this paper only the measurements taken in the foundation, as we focus on the erosion occurring in that part of the dike.

Figure 4 shows the evolution of the temperature before and during the test, for different distances from upstream. Before the beginning of the test, the temperature at the base of the dike is constant. Minor differences between the measuring lines, within $1^{\circ} \mathrm{C}$, are a consequence of different exposition (south or north) and depth. 


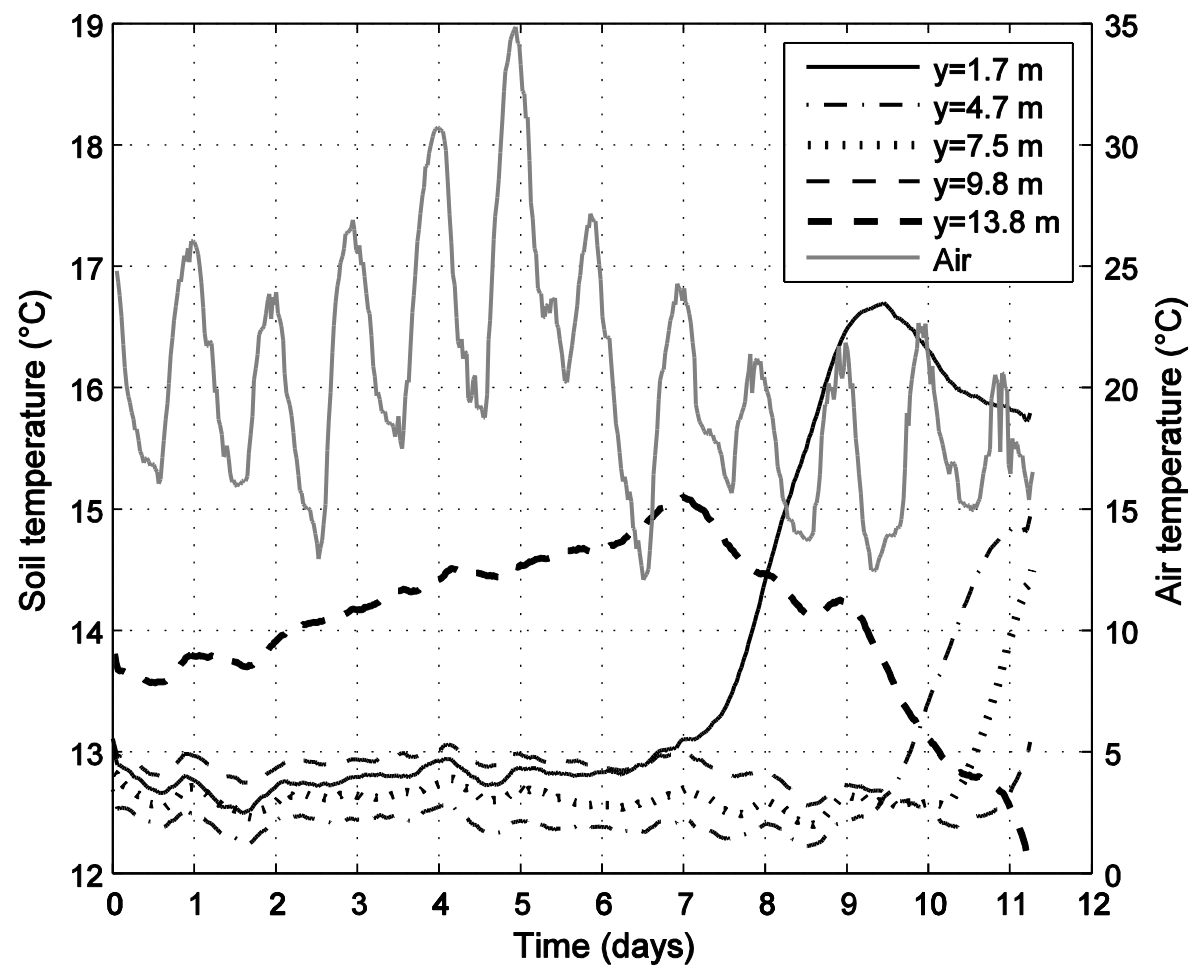

\section{Figure 4 Temperature measured in the centre of the dike $(x=10 \mathrm{~m})$ at progressive distance from upstream $(y)$}

The temperature at the most downstream position (Line 5) is strongly influenced by the external environment. It shows a positive trend, up to the beginning of the test (at $t=7$ days), likely as a consequence of increasing solar radiation. Subsequently a sharp inversion of trend occurs. On the other hand, the temperature at Line 1, placed at $1.7 \mathrm{~m}$ from the upstream toe, starts increasing few hours after the beginning of the test, which means that the reservoir water was warmer than the dike body. Lines 2 and 3 are reached by the warm front after 2 and 3 days respectively. At Line 4 , the temperature starts decreasing soon after the beginning of the test and it keeps decreasing up to the arrival of the warm front, more than 3 days later. Line 5 was never reached by the warm front.

Figure 5 depicts the temperature measured by Line 5, placed at $1.2 \mathrm{~m}$ from the downstream toe and between the third and fourth line of pore pressure transducers. Although differentiating among the measurements is not possible, the graph clearly shows that the temperature values start to diverge at $55 \mathrm{~h}$, which is when the third line of pore pressure metres is reached by the pipes. No sign is detected earlier, at $43 \mathrm{~h}$, when the fourth line of pore pressure sensors is reached. The graph also shows that the measured temperature variations are smaller than $1^{\circ} \mathrm{C}$. Temperature data recorded along Line 4 did not show any anomaly. This is in accordance with the pore pressure measurements, since this optical fibre is upstream of the second line of pore pressure sensors that was never reached by the pipes.

A graphical representation of the same data using a spectrogram, as in Figure 6 , is very effective for identifying the occurrence of piping. Starting from $55 \mathrm{~h}$, negative thermal anomalies (lower temperature) appear at the location of the pipes, approximate at $x=5,11$ and $17 \mathrm{~m}$. Since the reservoir water was warmer than the dike, positive anomalies would be expected; the reason for this non-intuitive behaviour will be explained later. From experience, we prefer a monochrome to other colour scales; otherwise, we suggest comparing the results of coloured and monochrome colour scales.

A careful look at contours plotted for significant times during the test, as reported in Figure 7, reveals how the pipes generate the thermal anomalies shown in Figure 5 and 6. 


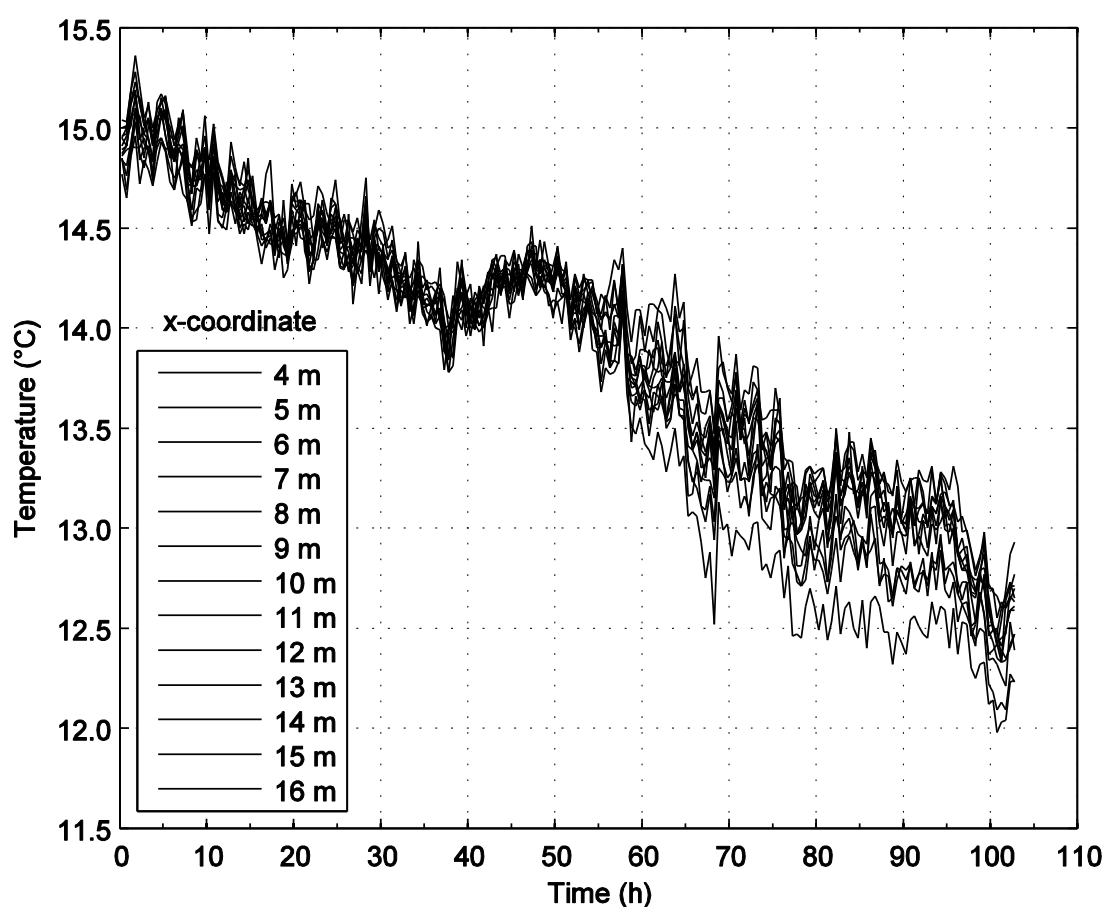

Figure 5 Temperature measured at the most downstream line $(y=13.8 \mathrm{~m})$

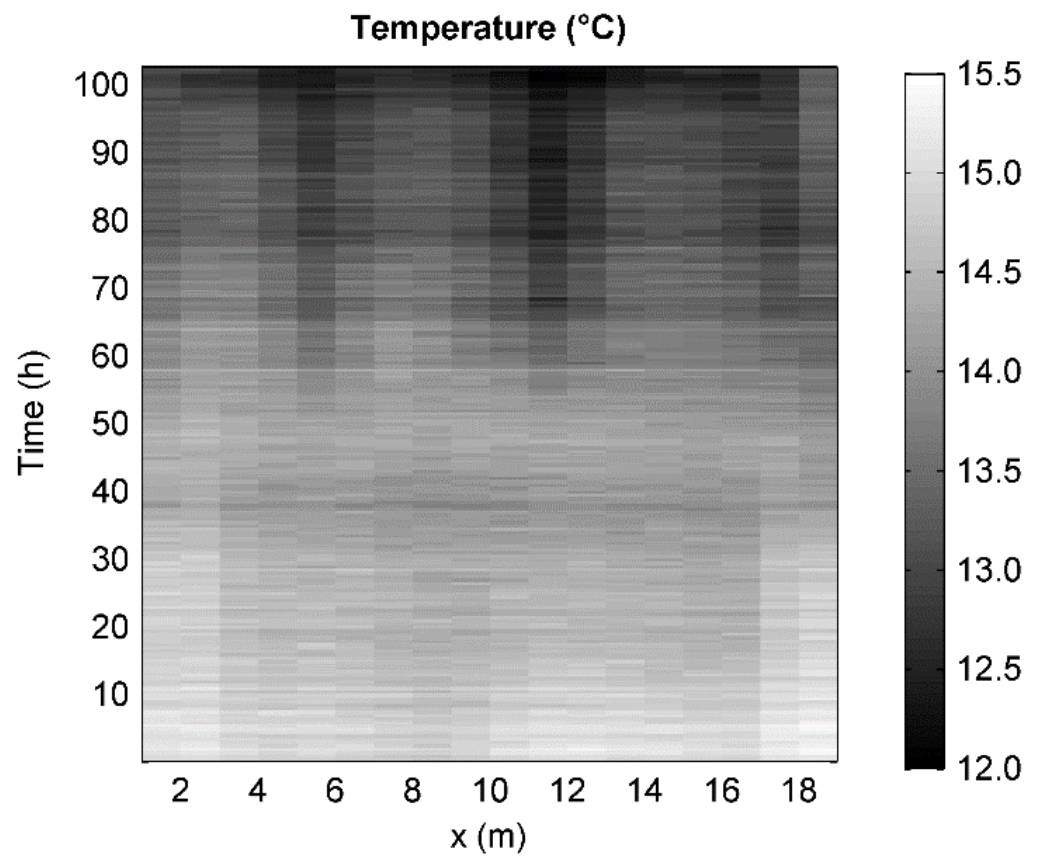

Figure 6 Temperature measured at the most downstream line $(y=13.8 \mathrm{~m})$ plotted as a spectrogram

A minor detail to notice is that the temperature is not uniform along the $x$-axis (except downstream), neither in absence of flow $(t=0)$ nor with seepage flow. The temperature is higher at the centre than at the borders. This can be ascribed to the 'three-dimensionality' of the piping facility, in opposition to a real dike where the large extension in the longitudinal direction with respect to the transversal dimension makes the problem bi-dimensional.

More importantly, it can be noted that the inflowing water causes the temperature to increase upstream, and pushes the cold water, initially present under the dike crest, towards downstream. When the pipes 
develop, temperature variations arise in their surroundings because the cold water coming from underneath the dike crest travels faster in the pipes.
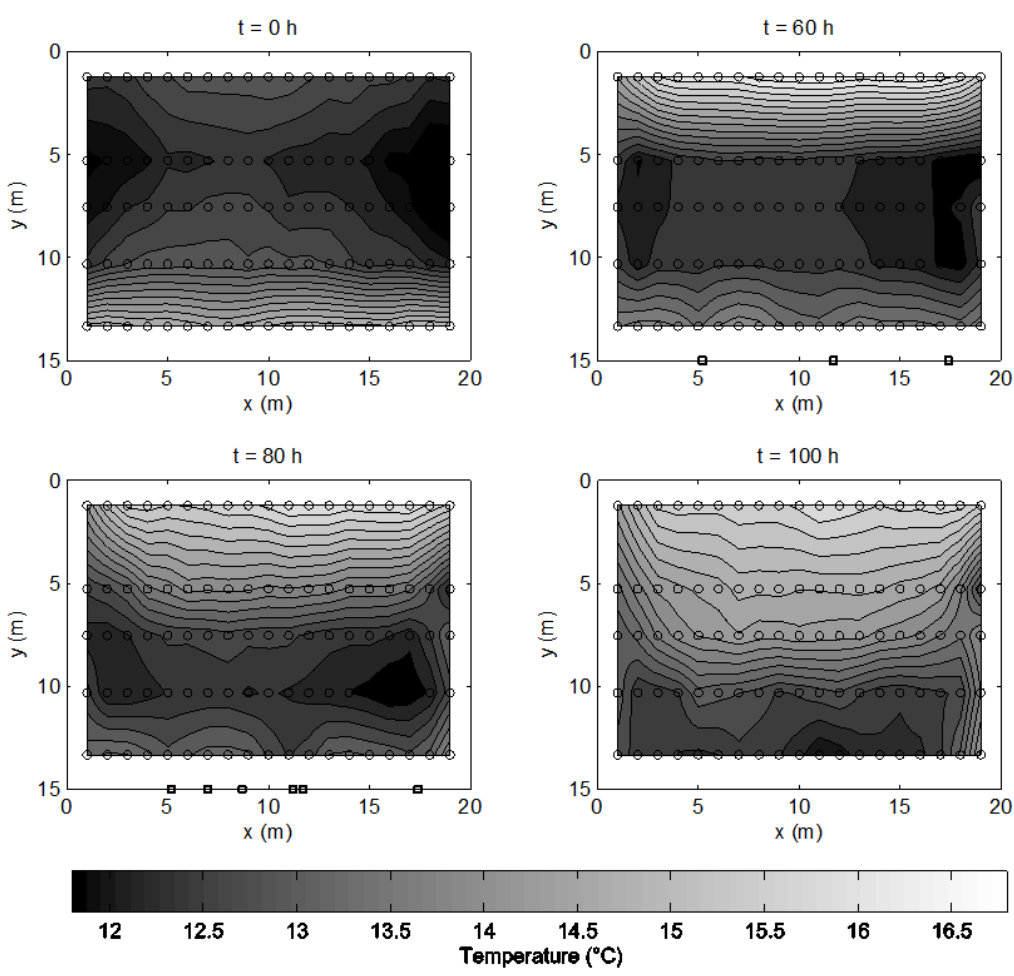

\section{Figure 7 Temperature under the dike at $0,45,60,80$ and 100 hours from the beginning of the test. The circles indicate the points at which real data were provided for interpolation. The squares on the $\mathrm{x}$-axis indicate the position of the sand boils}

In addition, in the $100 \mathrm{~h}$ contour plot, preferential flow paths can be observed at the sides, that bring warm water downstream faster than how it travels in the centre of the dike. This is more pronounced at the right side. As no sand boil was observed at the sides, these preferential paths are believed to be a consequence of the discontinuity between the soil and the impermeable foil. These minor leakages could not be identified by the interpretation of the pore pressure readings.

\section{Discussion}

\subsection{Heat transfer under a dike}

Whether a thermal front can propagate in the dike foundation from upstream up to the downstream toe depends on several factors: main actor is the hydraulic conductivity of the soil, but a role is also played by the geometry of the seepage domain (Van der Kamp \& Bachu 1989). We inferred from the test that the time factor also plays a significant role and cannot be neglected when studying how heat is transferred under a dike. Indeed, we observed that the time scale of the process of heat propagation along the seepage path can be comparable with the duration of typical flood events. Differently from what happens to porewater pressure, which transmission can be assimilated to that of a body wave, heat transfer by advection requires that the water particle entered upstream reaches downstream while maintaining its initial temperature. As a consequence, heat 'travels' much slower than porewater pressure.

In situations like the one presented here, where the thermal front does not propagate much along the seepage path, a second phenomenon might allow leakages to produce thermal anomalies.

At the dike toe, the piping prone layer can be close enough to the surface to be influenced by external temperature. Soil temperature is strongly affected by external temperature up to $1 \mathrm{~m}$ depth. This effect is masked when seepage flows of high velocity occurs. 
In our test dike, the soil temperature measured downstream was affected by the external temperature in absence of flow. As seepage occurred, the flow velocity was everywhere high enough to alter the initial gradient. However, the gradient in the seepage direction varied faster at the pipe locations than in the sound part of the dike, producing the thermal anomalies observed. The temperature gradient in the seepage direction is shown in Figure 8 for two locations: one close to a pipe $(x=11 \mathrm{~m})$ and one not affected by piping $(x=14 \mathrm{~m})$. The graph also show that, at the pipe location, after $90 \mathrm{~h}$ the gradient turns negative, meaning that the warm thermal front coming from upstream has reached the head of the pipe.

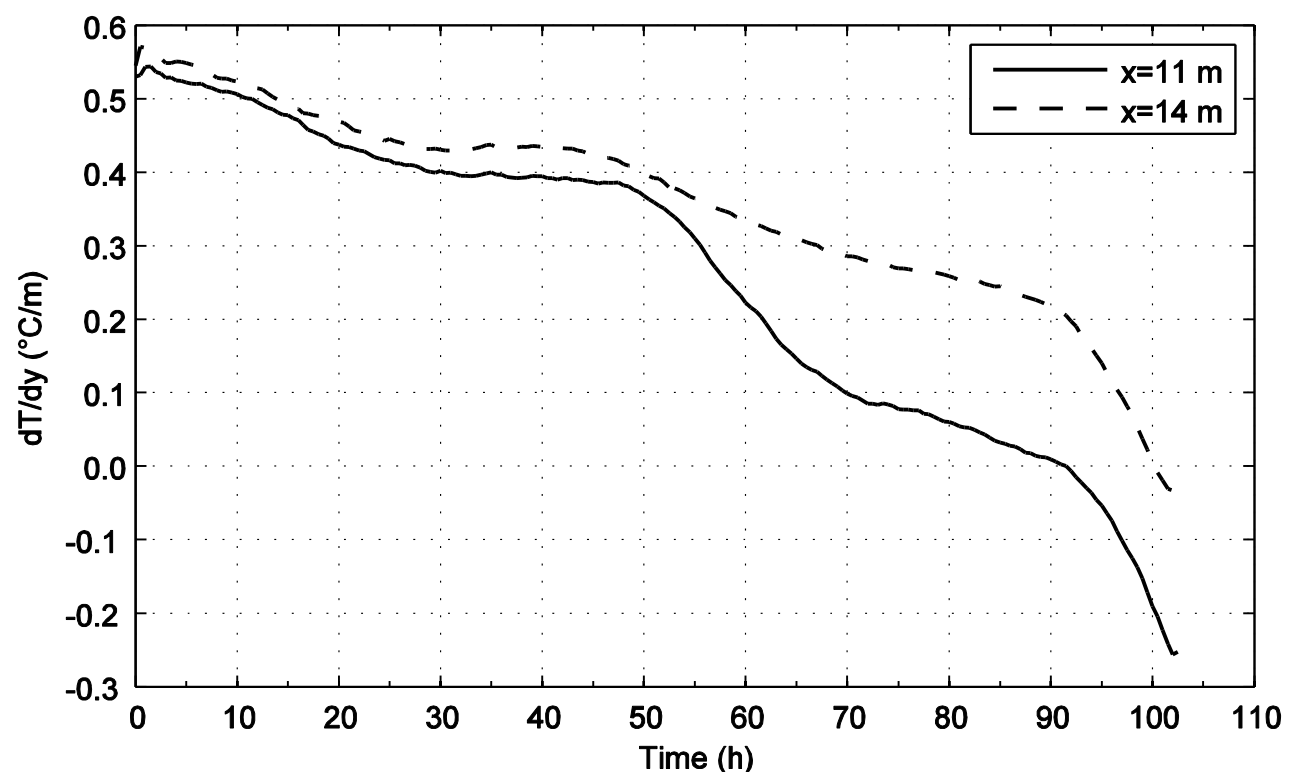

Figure 8 Temperature gradients in the direction of the seepage flow at a location where piping was observed

$(x=11 \mathrm{~m})$ and at a location where no piping was detected $(x=14 \mathrm{~m})$

\subsection{Real-time identification of leakages}

Although appropriate graphical representation of data can be effective in identifying leakages ex post, real-time identification requires quantitative and automatable criteria. Figure 9 shows the spatial temperature gradients calculated along the most downstream measuring line.

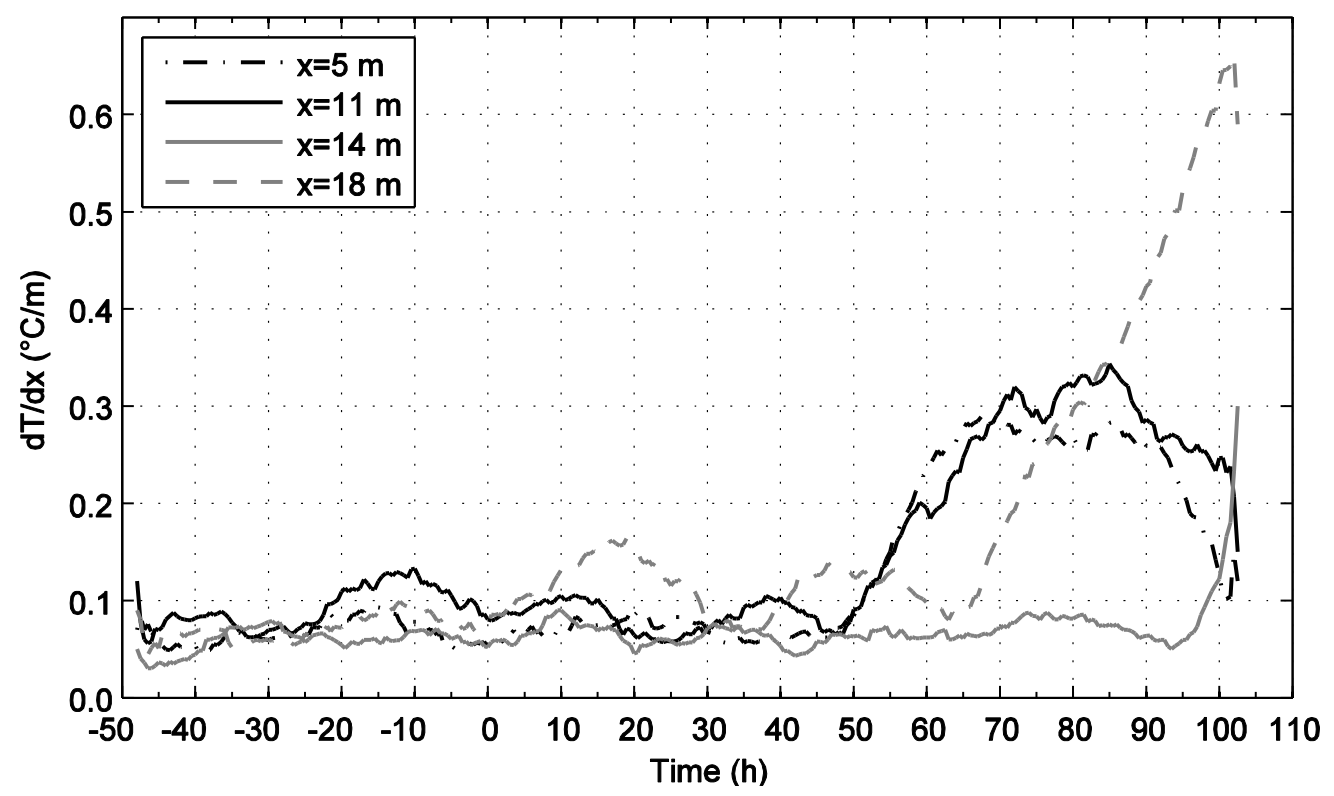

Figure 9 Spatial temperature gradients for significant points along the most downstream line 
At the locations of $x=5 \mathrm{~m}$ and $\mathrm{x}=11 \mathrm{~m}$, where sand-boils have been observed, the gradients start to increase at $50 \mathrm{~h}$, reach a value of about 0.3 and stabilise between about 65 and $85 \mathrm{~h}$, when the drainage tube is open. The gradients decrease when, after $85 \mathrm{~h}$, the hydraulic load is increased continuously. A possible explanation is that new sand boils appeared and old pipes branched, so that a new 'homogeneous' condition was reached, in which most of the dike was affected by piping.

At $x=18 \mathrm{~m}$, where a sand-boil was observed starting from $60 \mathrm{~h}$, the high spatial gradient comes from the superposition of two effects: the negative anomaly caused by piping at that location and the positive anomaly caused by the leakage along the foil at $x=19 \mathrm{~m}$.

For comparison, the graph also reports the gradients at $x=14 \mathrm{~m}$ where no sand boil was observed, at least not up to $90 \mathrm{~h}$ when visual inspection was stopped for safety reasons.

\subsection{Performance of the DTS system}

The $1 \mathrm{~m}$ spatial resolution of the sensor is much larger than the width of a single pipe (few centimetres). For this reason, it was initially believed to be partially liable for the small extent of the temperature variations detected. However, when the pipes developed, the temperature difference between Lines 4 and 5 , which was responsible for the anomalies around the pipes, was less than $1^{\circ} \mathrm{C}$. Thus, the measurements would not probably have benefited from a higher spatial resolution. The development of a branched net of pipes behind a single sand boil, as observed in medium-scale experiments (Weijers \& Sellmeijer 1993), could be helpful in this sense.

The accuracy of $0.1^{\circ} \mathrm{C}$ was sufficient but higher accuracy could be advantageous.

\section{Conclusion}

In a large-scale dike failure experiment including backward erosion as collapse mechanism, both porewater pressure and temperature have been measured extensively to detect the piping process. Pressure was measured by traditional electrical transducers while temperature was measured by optical fibres.

Analysis of the measurements is oriented at understanding the effectiveness of thermometry in detecting piping occurring under river and sea dikes.

Accuracy and spatial resolution of the DTS system proved to be sufficient to detect piping in the test dike. For piping detection in dikes, we advise against installation of systems with lower accuracy and spatial resolution. A frequency of two measurements per hour was judged by the test leaders not appropriate for a real-time warning system. Planning the desired acquisition frequency in advance with the system supplier is important, because sometimes, in DTS systems, the adjustment of the acquisition frequency can be performed only at the expenses of accuracy and spatial resolution.

For piping channels to generate thermal anomalies, it is not sufficient that a temperature gradient exists between the reservoir water and the dike: a horizontal temperature gradient in the sound soil and at the sides of the pipe, between the head and the tail of the pipe, is needed. In our test dike, the temperature gradient between the centre and toe of the dike was mainly responsible for piping detection, due to the limited depth of the layer where piping occurred (and where the sensors were placed). Only towards the end of the test, the warm thermal front coming from upstream reached the head of the pipes, and the gradient between reservoir water and initial soil temperature became helpful for piping detection.

We can thus assert that during the test two mechanisms subsequently developed that allowed continuous detection of the pipes. Were we just lucky? In real dikes, the soil layer prone to piping is often overlain by a less permeable layer (blanket) and thus farer from the surface than in the test dike. Whether the effect of the external temperature can be exploited at greater depths will be matter for further investigations.

We have shown that the temperature gradient along the fibre is a measure suitable for real-time identification of the leakages. The threshold values should be determined after an observation period, as spatial gradients might also develop at some locations for reasons other than piping, as heterogeneity. 
A number of site-specific factors influence the temperature gradient under a dike, determining the success or failure of a passive DTS in identifying piping occurrence. In order to evaluate in advance whether a passive monitoring system will be effective, it is important to have a reliable heat transfer model of the dike, which can be produced by numerical modelling. Commercial finite elements or finite differences software is available for coupled modelling of heat transfer and seepage flow in porous media. As the duration of typical flood events might be comparable with the time scale of the heat propagation process along the seepage path, a transient analysis is recommended. This is a major difference with embankment dams, where the reservoir temperature is assumed to vary cyclically in time, but seepage velocity is assumed constant. In order to obtain an accurate heat transfer model, reliable hydraulic conductivity input data are paramount, which can only be obtained through pore pressure monitoring, pumping tests, or tracer tests.

We believe that the reliability of an active DTS system is higher, as it does not depend on the natural temperature gradients under the dike. The marginal cost of an active system with reference to a passive system is not high, if compared to the amount of additional information it can provide. Considering that heating the cables is highly power consuming, it is possible to perform active measurements mainly during flood events while passive measurements can be collected continuously throughout the year.

\section{References}

Beck, YL, Khan, AA, Cunat, P, Guidoux, G, Artieres, O, Mars, J \& Fry, JJ 2010, 'Thermal monitoring of embankment dams by fiber optics', Proceedings of the 8th ICOLD European Club Symposium on Dam Safety, International Commission on Large Dams, Paris, France, pp. 444-447.

Cirio, CG, Bossuto, P \& Viale, F 2004, 'Quadro conoscitivo sulle rotte nell'arginatura maestra del Po documentate a partire dal 1800 lungo il percorso fluviale da Zerbo (PV) a Serravalle (FE)', CNR-IRPI Sezione di Torino.

Dornstädter, J 2013, 'Leakage detection in dams - state of the art', 20th SLOCOLD, Ljubljana.

Fry, J-J 1997, 'Internal erosion and surveillance', ICOLD 19th Congress, Florence, vol. V, pp. 255-268.

Henault, JM, Moreau, G, Blairon, S, Salin, J, Courivaud, JR, Taillade, F, Merliot, E, Dubois, JP, Bertrand, J, Buschaert, S, Mayer, S \& Depine-Lesoille, S 2010, 'Truly distributed optical fiber sensors for structural health monitoring: from the telecommunication optical fiber drawling tower to water leakage detection in dikes and concrete structure strain monitoring', Advances in Civil Engineering, vol. 2010, 13 p.

ICOLD 2015, International Commission on Large Dams, 'Internal erosion of existing dams, levees and dikes, and their foundations Volume 1: Internal erosion processes and engineering assessment', Bulletin of ICOLD, no. 164.

Johansson, S \& Sjödahl, P 2004, 'Downstream seepage detection using temperature measurements and visual inspection monitoring experiences from Røsvatn field test dam and large embankment dams in Sweden', Proceedings of the International Seminar on Stability and Breaching of Embankment Dams, EBL, Oslo, $20 \mathrm{p}$.

Johansson, S \& Sjödahl, P 2009, 'A guide for seepage monitoring of embankment dams using temperature measurements', Canadian Electricity Association, report no. T062700.

Kamp, van der, G \& Bachu, S 1989, 'Use of dimensional analysis in the study of thermal effects of various hydrogeological regimes', Hydrogeological regimes and their subsurface thermal effects, vol. 47, pp. 23-28.

Koelewijn, AR, de Vries, G \& van Lottum, H 2013, 'Full-scale field validation of innovative dike monitoring systems', Proceedings of the 18th International Conference on Soil Mechanics and Geotechnical Engineering, Paris.

Koelewijn, AR, de Vries, G, van Lottum, H, Förster, U, van Beek, VM \& Bezuijen, A 2014, 'Full-scale testing of piping prevention measures: three tests at the IJkdijk', Proceedings of the 8th International Conference on Physical modelling in Geotechnics, Centre for Offshore Foundation Systems, Perth, pp. 891-897.

Sheffer, MR, Johansson, S \& Sjödahl, P 2009, 'Recent developments in the use of temperature, resistivity and self-potential methods for monitoring embankment dam performance', Proceedings of the Canadian Dam Association Annual Conference, Canadian Dam Association, Toronto.

Vries, de, G, Brake, ter, CKE, Bruijn, de, H, Koelewijn, AR, Langius, EAF, Lottum, van, H \& Zomer, WS 2013, 'Dike monitoring: evaluation of measurement techniques and visualization systems, Final report All-In-One Sensor Validation Test', STOWA/Stichting IJkdijk, Amersfoort, The Netherlands [in Dutch].

Vrijling, JK 2010, Piping - Realiteit of Rekenfout?, Rijkswaterstaat, Waterdienst [in Dutch].

Weijers, JBA \& Sellmeijer, JB 1993, 'A new model to deal with the piping mechanism on filters', in J Brauns, M Heibaum \& U Schuler (eds), Filters in geotechnical and hydraulic engineering, Balkema, Rotterdam, pp. 349-355. 